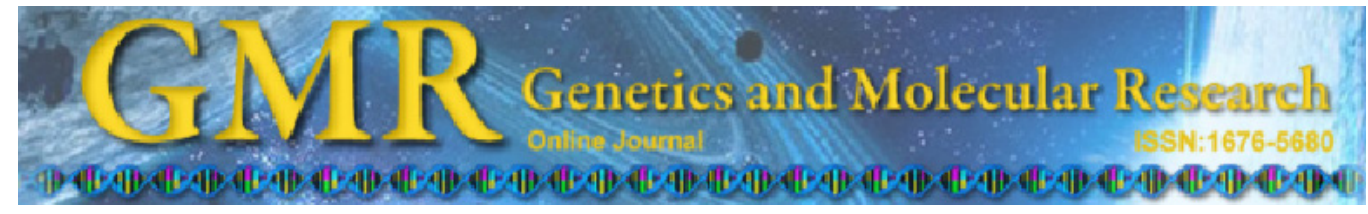

\title{
Immunohistochemical and molecular analysis of caveolin-1 expression in canine mammary tumors
}

\author{
D.A.P.C. Zuccari ${ }^{1,2}$, R. Castro ${ }^{1}$, A.F. Gavioli ${ }^{4}$, U.M. Mancini ${ }^{3}$, C.S. Frade ${ }^{1}$ \\ and C. Leonel ${ }^{1,2}$ \\ ${ }^{1}$ Laboratório de Investigação Molecular do Câncer, \\ Faculdade de Medicina de São José do Rio Preto, \\ São José do Rio Preto, SP, Brasil \\ ${ }^{2}$ Programa de Pós-Graduação em Genética, \\ Universidade Estadual Paulista "Júlio de Mesquita Filho", \\ São José do Rio Preto, SP, Brasil \\ ${ }^{3}$ Laboratório de Marcadores Moleculares e Bioinformática Médica, \\ Faculdade de Medicina de São José do Rio Preto, \\ São José do Rio Preto, SP, Brasil \\ ${ }^{4}$ Laboratório de Virologia, Faculdade de Medicina de São José do Rio Preto, \\ São José do Rio Preto, SP, Brasil \\ Corresponding author: D.A.P.C. Zuccari \\ E-mail: debora.zuccari@famerp.br \\ Genet. Mol. Res. 11 (1): 153-165 (2012) \\ Received May 5, 2011 \\ Accepted October 18, 2011 \\ Published January 27, 2012 \\ DOI http://dx.doi.org/10.4238/2012.January.27.2
}

\begin{abstract}
Caveolin-1 (Cav-1) is a structural protein present in invaginations of the cell membrane. In human breast cancer, the cav-1 gene is believed to be a tumor suppressor gene associated with inhibition of tumor metastasis. However, little is known about its expression, regulation and function in canine mammary tumors. Expression levels of cav-1 were investigated using real-time PCR and immunohistochemical detection with an anti-human Cav-1 antibody. Gene expression stability of different samples was analyzed using the geNorm software. Mammary tumors from 51 female dogs were
\end{abstract}


compared to normal mammary tissue from 10 female dogs. Malignant mammary cells showed a loss of Cav-1 expression by quantitative RTPCR and weak Cav-1 staining by immunohistochemistry compared to normal mammary gland tissue. There was a significant relationship between outcome and immunostaining as well as with tumor size, indicating that caveolin subexpression has a positive predictive value and is related to higher survival and smaller tumor size. Our findings indicate that Cav-1 is a potential prognostic marker for canine mammary tumors.

Key words: Mammary cancer; Prognosis; Immunohistochemistry; Quantitative PCR

\section{INTRODUCTION}

Caveolin-1 (Cav-1) is a structural protein of 50 to $100 \mathrm{~nm}$ present in invaginations of the cell membrane (caveolae) (Bat'ová et al., 2003; Williams and Lisanti, 2005; Sotgia et al., 2006; Williams et al., 2006; Shajahan et al., 2007). Caveolae are enriched by sphingolipids and cholesterol (Zhu et al., 2008) and are directly involved in vesicular trafficking and signal transduction (Bouras et al., 2004; Chen et al., 2004; Elsheikh et al., 2008). Caveolae and caveolins have several functions including vesicular transport, cholesterol homeostasis, signal transduction, and tumor suppression (Bat'ová et al., 2003). Caveolin-1 is a phosphorylated tyrosine with a molecular mass of $22 \mathrm{kDa}$ (Williams and Lisanti, 2005) and it primarily acts as an inhibitor of mitotic proliferation in different cell types, including mammary gland epithelial cells (Bouras et al., 2004; Chen et al., 2004; Sloan et al., 2004; Williams and Lisanti, 2005; Glait et al., 2006). Decreased Cav-1 expression has been reported in oncogenic transformation of fibroblasts (Mercier et al., 2008).

In humans, the caveolin-1 gene (cav-1) is believed to be a tumor suppressor gene (Williams et al., 2006; Sotgia et al., 2006; Savage et al., 2007) and decreased Cav-1 expression has been reported in breast cancer. The gene is located on chromosome 7, locus D7S522, with fragile site q31.1 (Williams et al., 2006). A deletion in the 7q31.1/D7S522 region of cav1 has been associated with human breast cancer (Lee et al., 2002). In contrast, a significant increase in caveolin-1 expression has been found in one third of evaluated invasive breast cancers in women when compared with benign lesions and healthy mammary gland tissue, by another group of researchers (Liedtke et al., 2007). In cultured cells, Cav-1 expression levels are reduced, unchanged or up-regulated depending on the tumor cell type (Williams and Lisanti, 2005). For instance, Cav-1 down-regulation is typical for ovarian, lung, and mammary carcinomas as well as for mesenchymal sarcomas. On the other hand, Cav-1 has been reported to be up-regulated in bladder, esophagus, thyroid (papillary subtype), and prostate carcinomas (Williams and Lisanti, 2005).

However, Williams and Lisanti (2005) and Amorim et al. (2010) found that caveolin-1 overexpression was correlated with metastasis in esophageal squamous cell carcinoma, clear cell renal cell carcinoma, mammary adenocarcinoma, and metastatic cell lines derived from lung adenocarcinoma. These results have implications for human cancers where Cav-1 is consistently up-regulated and suggest that the up-regulation of Cav-1 may represent an 
acquired feature that contributes to a metastatic phenotype. This concept of a "biphasic" expression pattern for Cav-1 was elegantly demonstrated in colon carcinoma cells after selection for metastatic variants (Williams et al., 2004; Williams and Lisanti, 2005).

Caveolin-1 expression patterns have not been reported in canine mammary tumors. The aim of this study was to evaluate $\mathrm{Cav}-1$ expression in these tumors and suggest its value as a prognostic marker.

\section{MATERIAL AND METHODS}

\section{Specimens}

Mammary tumors from 51 female dogs undergoing surgical extirpation were evaluated and followed-up for 18 months. The dogs ranged from age 2 to 17 years (mean 10 years) and most were of mixed breeds. According to Sorenmo et al. (2009) and Ferreira et al. (2009) models, the staging tests included routine bloodwork (complete blood count, serum chemistry profile), urinalysis, fine needle aspirates of palpable draining lymph nodes, and thoracic radiological examinations. The mammary glands were examined carefully and all tumors were recorded and measured. The surgical resection was performed according to standard practice, with the aim of removing all tumor/tumors with complete margins. The type of surgery, i.e., lumpectomy, simple mastectomy or regional mastectomy depended on the tumor size, location and the number of tumors present in the individual dog. If necessary, the surgeries were staged in two phases in order to prevent excessive tissue tension and wound dehiscence in dogs with multiple large tumors.

Normal mammary gland tissues from 10 female dogs euthanized at the Zoonosis Control Center were used as a pool control in the molecular study and as controls for immunohistochemistry. In addition a human endothelial tissue fragment was used as immunohistochemical control.

\section{Histopathology}

Two samples were collected from each animal. The sample used in the molecular assays was frozen immediately after surgery, and the sample for immunohistochemistry was fixed in $10 \%$ buffered formaldehyde solution. Tissue blocks were prepared by standard histological methods, embedded in paraffin wax, sectioned at $5 \mu \mathrm{m}$ and stained with hematoxylin and eosin. Representative areas of the tumor were selected for immunohistochemistry.

All tumors were submitted for histopathological examination. Two independent pathologists performed the evaluations blinded to each other and all clinical information about the case. In cases of discordance a third pathologist was consulted and the chosen result was retained. The tumors were classified according to type of tissue present (epithelial, myoepithelial and/or connective tissue) and whether they were malignant or benign. The malignant sample epithelial tumors were grouped together as carcinomas for the purpose of this study and included tubulopapillary carcinoma, solid carcinomas and complex carcinomas. The diagnosis also included histopathological assessment of the entire section including dysplastic changes and was not limited to the neoplastic changes alone. The animals were followed-up 
for 18 months and the survival time was defined as the period (days) between surgical tumor removal and date of death caused by the disease (end point). The cause of death was confirmed by clinical data.

The histopathological classification was based on the World Health Organization classification system for canine mammary tumors (WHO, 2007); in addition, a TNM classification was used to evaluate tumor size $(\mathrm{T})$ : T1 $(0-3 \mathrm{~cm}), \mathrm{T} 2(3-5 \mathrm{~cm})$ and T3 $(>5 \mathrm{~cm})$, to regional lymph nodes $(\mathrm{N})$ metastasis: $\mathrm{N} 1$ (presence) and N0 (absence) and to the occurrence of distant metastasis (M): M1 (presence) and M0 (absence) (Ferreira et al., 2009).

\section{Clinical follow-up studies}

The dogs were reexamined regularly every 4 months and until 18 months after the surgery. They were diagnosed with metastasis or recurrence confirmed by chest X-ray, abdominal ultrasound, needle aspiration biopsy of the new lump, or necropsy, where the dog had died.

\section{Caveolin-1 immunostaining}

A section of at least one tissue block representing a characteristic area of the tumor of each of the 51 cases was mounted on silanized glass slides (Sigma-Aldrich, St. Louis, MO, USA). The slides were deparaffinized, rehydrated in graded alcohols, and incubated with 3\% hydrogen peroxidase (Farmax, Divinópolis, Brazil) for 30 min to block endogenous peroxidase activity. Antigen retrieval was performed on Pan Steam (Arno, São Paulo, Brazil) at $95^{\circ} \mathrm{C}$ with citric acid buffer, $\mathrm{pH} 6.0$, for $35 \mathrm{~min}$. After cooling to room temperature at $25^{\circ} \mathrm{C}$, the slides were covered with bovine serum albumin (Santa Cruz Biotechnology, Inc., Santa Cruz, CA, USA) for 30 min before incubation with the primary antibody for $2 \mathrm{~h}$ at room temperature, and the avidin-biotin-peroxidase complex (ABC) for $1 \mathrm{~h}$. A mouse monoclonal anti-human Cav-1 (clone 2297) (Transduction Labs, Lexington, KY, USA) diluted 1:150 in bovine serum albumin (BSA) was used as the primary antibody. Chromogen, 3,3'-diaminobenzidine tetrahydrochloride $0.5 \%$ (Signet ${ }^{\circledR}$, Dedham, MA, USA) diluted in phosphatebuffered saline was applied to the slides for $2-5 \mathrm{~min}$ at $20-22^{\circ} \mathrm{C}$. Slides were subsequently counterstained with Harris's hematoxylin.

Negative controls were obtained by omitting the primary antibody, whereas normal mammary gland tissue was used as an internal positive control in each assay. Expression of the marker was evaluated according to the grading by Allred et al. (1998).

\section{Evaluation of immunohistochemical data}

Multiple fields of each slide were examined and positive immunostaining was indicated by the presence of distinct brown cytoplasmatic staining (Figure 1). Immunohistochemical examination was blinded (i.e., without knowledge of the histopathological diagnosis) and the results were based on the consensus of at least two observers. A number of 1000 cells were evaluated in 10 fields (400X magnification) to assess positive cell (PC) percentage. The results were grouped into semiquantitative scores as negative, focal $(<10 \% \mathrm{PC})$, weak (10-25\% PC), moderate (25-50\% PC), or strong (>50\% PC). 


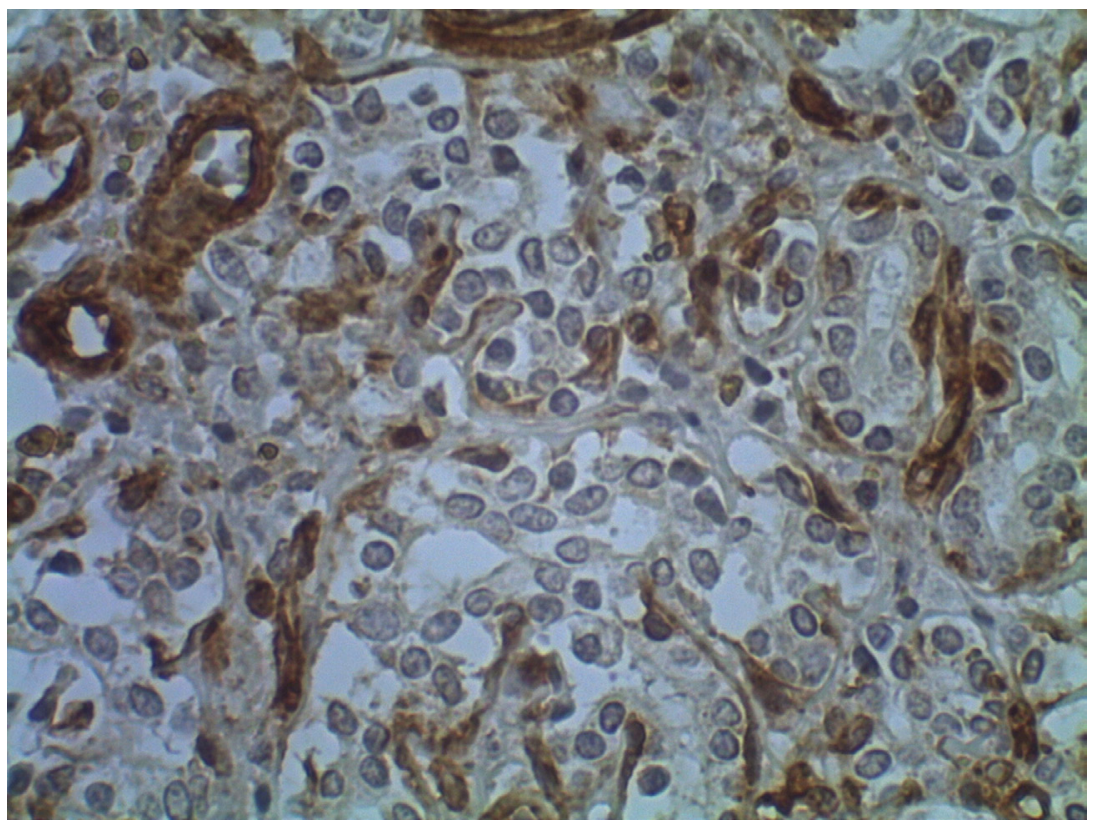

Figure 1. Immunohistochemistry of a solid carcinoma (Dog 28) with strong expression of caveolin-1. Notice the dark cytoplasmatic staining. Mouse monoclonal anti-human caveolin, avidin-biotin-peroxidase, diaminobenzidine tetrahydrochloride chromogen, counterstained with Harris's hematoxylin. Magnification $=40 \mathrm{X}$.

\section{Quantitative RT-PCR}

A quantitative real-time (RT) PCR was performed in triplicate using an ABI Prism 7500 Sequence Detection System (Applied Biosystems, Foster City, CA, USA). Briefly, the reactions were performed in $20 \mu \mathrm{L}$ with $10 \mu \mathrm{L}$ Power SYBR Green PCR Master Mix (Applied Biosystems, São Paulo, Brazil), $250 \mathrm{nM}$ of each primer and $10 \mathrm{ng}$ cDNA. The PCR conditions were $50^{\circ} \mathrm{C}$ for $2 \mathrm{~min}, 95^{\circ} \mathrm{C}$ for $10 \mathrm{~min}$ followed by 35 cycles of $95^{\circ} \mathrm{C}$ for $15 \mathrm{~s}, 60^{\circ} \mathrm{C}$ for $1 \mathrm{~min}$. Following the PCR, dissociation curve analysis was performed to confirm the desired singlegene product: 1 cycle of $95^{\circ} \mathrm{C}$ for $15 \mathrm{~s}, 60^{\circ} \mathrm{C}$ for $1 \mathrm{~min}, 95^{\circ} \mathrm{C}$ for $15 \mathrm{~s}$.

Expression of five housekeeping genes (ACTB, GAPD, GUSB, PPIA, and HPRT1) was first tested in 15 breast cancer samples (Vandesompele et al., 2002) and expression of HPRT1 and was considered to be the most stable among samples. HPRT1 was then chosen as a reference gene. Investigated transcripts showed high real-time PCR efficiency rates (approximately 1.0) and relative expression was calculated as $2^{-\Delta \Delta C T}$. Results were then transformed into their natural logarithm values. Gene expression stability was analyzed by the geNorm software.

All the reactions were performed with a negative control and one sample was selected as the calibrator control for the reactions. Analyses were repeated when the coefficient of variation was higher than $5 \%$. After each reaction, the products were analyzed on a $2 \%$ agarose gel stained with ethidium bromide.

Primers used for amplification were: CAVEOLIN-1 sense (5'-ACAGCAAGCGG TAAAACCAG-3') and antisense (5'-ACACCAAGGAAATCGACCTG-3'); and HPRT1 (en- 
dogenous control), sense (5'-TTA TAG TCA AGG GCA TAT CC-3') and antisense (5'-AGC TTG CTG GTG AAA AGG AC-3'). They were classified into underexpressed (the samples obtained less than $-1 \log 3$ measurement) and overexpressed (the samples with quantification over $1 \log 3)$.

\section{Statistical analysis}

Multivariant logistic regression analyses of prognostic factors were performed. Results were analyzed on the basis of tumor diagnosis and animal outcome compared to immunohistochemical expression of the antibodies by analysis of dependency (Cordeiro, 1987). The differences of means between groups were assessed by the Student $t$-test. $\mathrm{P}<0.05$ was considered to be significant (two-tail analyses). The Kaplan Meier analysis was performed for survival based on the results of RT-PCR (overexpression/subexpression) and immunohistochemistry (moderate or severe/focal or weak) (Figure 2). All statistical analysis was performed using the Microsoft office XP Software (Minitab, version 12.22).
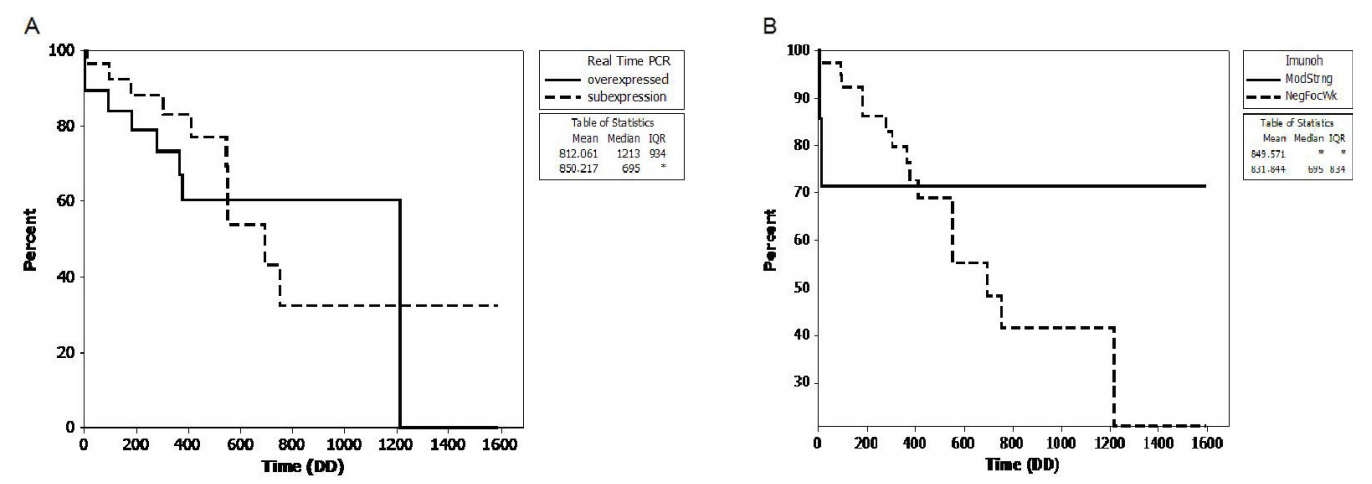

Figure 2. Kaplan Meier method showing no significance in the expression of the cav-1 gene by real-time PCR (A) and by immunohistochemistry (B) related to overall survival.

\section{RESULTS}

Evaluation of normal mammary tissue showed no expression of Cav-1 by luminal epithelial cells, while the basal/myoepithelial cells always exhibited strong labeling in both lobular and ductal units. Cav-1 expression was also consistently found in adipocytes, endothelial cells and stromal fibroblasts around the mammary glandular tissue; therefore, these structures were used as positive internal controls (Pereira et al., 2010).

The complete data on the 51 dogs based on individual histopathological diagnoses, immunohistochemistry, RT-PCR, clinical status 18 months after surgery, time period between surgery and reoccurrence of disease and TNM classification are available in Table 1 (individual data). The histopathological evaluation of the benign mammary tumors showed two mixed benign, one adenoma and one ductal hyperplasia. The histopathological evaluation of the malignant mammary tumors showed a predominance of carcinomas $(\mathrm{N}=44)$. Simple-type carcinomas dominated in the group $(\mathrm{N}=31)$ consisting of both tubulopapillary $(\mathrm{N}=19)$ and 
solid $(\mathrm{N}=12)$ subtypes. Complex carcinomas were found in $7 \mathrm{dogs}$, while one had a carcinoma with squamous cell differentiation. Carcinosarcomas were diagnosed in 5 dogs based on the presence of malignancy cellular criteria and metaplasia. Sarcoma was diagnosed in three cases.

Table 1. Immunohistochemistry and molecular expression of caveolin-1, histopathological diagnosis, outcome of the disease and disease-free interval of mammary tumors from 51 dogs.

\begin{tabular}{|c|c|c|c|c|c|c|}
\hline Sample & Histopatologic diagnosis & Immunohistochemistry* & Real-time PCR & Outcome & Disease-free interval & TNM \\
\hline 01 & Tubulopapillary carcinoma & $9 \%$ Focal & Subexpressed & Death-metastasis & Between 6-18 months & $\mathrm{T} 2 \mathrm{~N} 1 \mathrm{M} 0$ \\
\hline 02 & Carcinosarcoma & $5.5 \%$ Focal & Subexpressed & Death-metastasis & Less than 6 months & T3N0M0 \\
\hline 03 & Tubulopapillary carcinoma & $2 \%$ Focal & Overexpressed & Alive & More than 18 months & T3N0M0 \\
\hline 04 & Solid carcinoma & $0.3 \%$ Focal & Overexpressed & Death-metastasis & Between 6-18 months & T2N0M0 \\
\hline 05 & Complex carcinoma & $3.6 \%$ Focal & Overexpressed & Alive-recurrence & More than 18 months & T1N0M0 \\
\hline 06 & Solid carcinoma & $0.8 \%$ Focal & Overexpressed & Death-recurrence & More than 18 months & T2N0M0 \\
\hline 07 & Fibrosarcoma & $0.2 \%$ Focal & Overexpressed & Alive & More than 18 months & T3N0M1 \\
\hline 08 & Tubulopapillary carcinoma & $4.7 \%$ Focal & Subexpressed & Death & More than 18 months & $\mathrm{T} 1 \mathrm{~N} 2 \mathrm{~N} 1$ \\
\hline 09 & Carcinosarcoma & $0.3 \%$ Focal & Subexpressed & Death-metastasis & Less than 6 months & T1N0M0 \\
\hline 10 & Solid carcinoma & $20.2 \%$ Weak & Subexpressed & Death-metastasis & Less than 6 months & $\mathrm{T} 2 \mathrm{~N} 2 \mathrm{M} 1$ \\
\hline 11 & Solid carcinoma & $8.2 \%$ Focal & Subexpressed & Death & More than 18 months & T3N0M0 \\
\hline 12 & Carcinosarcoma & Negative & Subexpressed & Alive & More than 18 months & T3N0M0 \\
\hline 13 & Complex carcinoma & $16.4 \%$ Weak & Subexpressed & Alive & More than 18 months & T1N0M0 \\
\hline 14 & Solid carcinoma & Negative & Subexpressed & Death-metastasis & More than 18 months & T2N0M1 \\
\hline 15 & Solid carcinoma & $13 \%$ Weak & Subexpressed & Death-metastasis & Between 6-18 months & T3N0M1 \\
\hline 16 & Tubulopapillary carcinoma & $0.3 \%$ Focal & Subexpressed & Alive & More than 18 months & T3NOM0 \\
\hline 17 & Spindle cell sarcoma & $32.4 \%$ Moderate & Subexpressed & Alive & More than 18 months & T3N0M0 \\
\hline 18 & Fibrosarcoma & $5.6 \%$ Focal & Subexpressed & Alive & More than 18 months & T1N0M0 \\
\hline 19 & Solid carcinoma & $7 \%$ Focal & Subexpressed & Alive & More than 18 months & T1N0M0 \\
\hline 20 & Tubulopapillary carcinoma & $52.7 \%$ Strong & Subexpressed & Alive & More than 18 months & T1N0M0 \\
\hline 21 & Solid carcinoma & $22 \%$ Weak & Overexpressed & Death-recurrence & Less than 6 months & $\mathrm{T} 2 \mathrm{~N} 1 \mathrm{M} 0$ \\
\hline 22 & Tubulopapillary carcinoma & $3 \%$ Focal & Subexpressed & Alive & More than 18 months & T3N0M0 \\
\hline 23 & Tubulopapillary carcinoma & $19.1 \%$ Weak & Subexpressed & Death-recurrence & More than 18 months & $\mathrm{T} 3 \mathrm{~N} 1 \mathrm{M} 0$ \\
\hline 24 & Complex carcinoma & $32.7 \%$ Moderate & Subexpressed & Alive & More than 18 months & T2NOMO \\
\hline 25 & Complex carcinoma & $12.7 \%$ Weak & Subexpressed & Death-metastasis & More than 18 months & T3N0M1 \\
\hline 26 & Tubulopapillary carcinoma & $22.7 \%$ Weak & Subexpressed & Alive-recurrence & More than 18 months & T3N1M1 \\
\hline 27 & Tubulopapillary carcinoma & $7.4 \%$ Focal & Subexpressed & Death-recurrence & Less than 6 months & T3NOM0 \\
\hline 28 & Solid carcinoma & $93.8 \%$ Strong & Subexpressed & Alive & More than 18 months & T1N0M0 \\
\hline 29 & Complex carcinoma & $16.7 \%$ Weak & Subexpressed & Death-recurrence & Between 6-18 months & $\mathrm{T} 2 \mathrm{NxMx}$ \\
\hline 30 & Carcinoma with squamous diff. & $1 \%$ Focal & Subexpressed & Death-recurrence & More than 18 months & $\mathrm{T} 2 \mathrm{~N} 0 \mathrm{M} 0$ \\
\hline 31 & Tubulopapillary carcinoma & $25.3 \%$ Moderate & Subexpressed & Alive & More than 18 months & T1N0M0 \\
\hline 32 & Tubulopapillary carcinoma & $60.5 \%$ Strong & Subexpressed & Alive & More than 18 months & T2N0M0 \\
\hline 33 & Complex carcinoma & $35.3 \%$ Moderate & Subexpressed & Alive & More than 18 months & T1N0M0 \\
\hline 34 & Tubulopapillary carcinoma & $39.6 \%$ Moderate & Subexpressed & Death-recurrence & More than 18 months & T3NOMO \\
\hline 35 & Carcinosarcoma & $9.7 \%$ Focal & Subexpressed & Alive & More than 18 months & T3N0M0 \\
\hline 36 & Complex carcinoma & $21.3 \%$ Weak & Overexpressed & Alive & More than 18 months & T1N0M0 \\
\hline 37 & Solid carcinoma & $13.4 \%$ Weak & Subexpressed & Alive & More than 18 months & T2N0M0 \\
\hline 38 & Tubulopapillary carcinoma & $45.7 \%$ Moderate & Subexpressed & Alive & More than 18 months & T1N0M0 \\
\hline 39 & Tubulopapillary carcinoma & $35.1 \%$ Moderate & Subexpressed & Alive & More than 18 months & T1N0M0 \\
\hline 40 & Tubulopapillary carcinoma & $0.2 \%$ Focal & Subexpressed & Alive & More than 18 months & T2NOMO \\
\hline 41 & Tubulopapillary carcinoma & $24.8 \%$ Weak & Subexpressed & Alive & More than 18 months & T1N0M0 \\
\hline 42 & Tubulopapillary carcinoma & $7.2 \%$ Focal & Subexpressed & Alive & More than 18 months & T1N0M0 \\
\hline 43 & Solid carcinoma & $78.1 \%$ Strong & Overexpressed & Alive & More than 18 months & T1N0M0 \\
\hline 44 & Solid carcinoma & $32.4 \%$ Moderate & Subexpressed & Alive & More than 18 months & T2NOM0 \\
\hline 45 & Tubulopapillary carcinoma & $10.7 \%$ Weak & Subexpressed & Alive & More than 18 months & T1N0M0 \\
\hline 46 & Carcinosarcoma & $15.6 \%$ Weak & Subexpressed & Death-metastasis & Less than 6 months & T3N0M0 \\
\hline 47 & Tubulopapillary carcinoma & $49.6 \%$ Moderate & Subexpressed & Alive & More than 18 months & $\mathrm{T} 1 \mathrm{~N} 1 \mathrm{M} 0$ \\
\hline 48 & Benign & Strong & Subexpressed & Alive & More than 18 months & $\mathrm{T} 2 \mathrm{~N} 0 \mathrm{M} 0$ \\
\hline 49 & Benign & Weak & Subexpressed & Alive & More than 18 months & T2N0M0 \\
\hline 50 & Benign & Weak & Subexpressed & Alive & More than 18 months & $\mathrm{T} 2 \mathrm{~N} 0 \mathrm{M} 0$ \\
\hline 51 & Benign & Focal & Subexpressed & Alive & More than 18 months & T1M0N0 \\
\hline
\end{tabular}

* Percentage of caveolin-1 expression in 1000 cells counted according to Allred et al. (1998) as: (-) negative or no cells stained; $(+)$ values until $10 \%$ of cells stained; $(++)$ values between 10 to $25 \%$; $(+++)$ values between 25 to $50 \%$, and $(++++)$ values above $50 \%$. 
The immunohistochemical examinations of $\mathrm{Cav}-1$ demonstrated a correlation between the Cav-1 expression and histopathological diagnosis (Table 2). Carcinomas and sarcomas were either predominantly focal or weak. A comparison between the overall survival time and the histopathological diagnosis did not demonstrate a statistical positive concordance (Table 3).

Table 2. Correlation between histopathological diagnosis and caveolin-1 expression in 51 canine mammary gland tumors.

\begin{tabular}{lcr}
\hline Histopathological diagnosis & \multicolumn{2}{c}{ Immunohistochemical staining* } \\
\cline { 2 - 3 } & Negative/focal/weak & Moderate/strong \\
\hline Simple & 21 & 10 \\
Complex & 10 & 2 \\
Sarcoma & 2 & 1 \\
Squamous & 1 & 0 \\
Benign & 3 & 1 \\
All & 37 & 14 \\
\hline
\end{tabular}

*Grading is based on semiquantitative score.

Table 3. Correlation between histopathological diagnosis and overall survival time for 51 dogs having mammary gland neoplasia.

\begin{tabular}{llrr}
\hline Histopathological diagnosis & \multicolumn{2}{c}{ Overall survival time in months } \\
\cline { 2 - 4 } & $<6$ & $6-18$ & $>18$ \\
\hline Simple & 3 & 3 & 25 \\
Complex & 3 & 1 & 8 \\
Sarcoma & 0 & 0 & 3 \\
Squamous & 0 & 0 & 1 \\
Benign & 0 & 4 & 4 \\
All & 6 & 41 \\
\hline
\end{tabular}

As described in Table 4, the relationship between outcome and tumor size was statistically significant $(\mathrm{P}=0.011)$. Also, the relationship between outcome and immunostaining demonstrated a positive concordance $(\mathrm{P}=0.005)$ (Table 5).

\begin{tabular}{lcccc}
\multicolumn{5}{l}{ Table 4. Statistical correlation between outcome and tumor size. } \\
\hline Outcome & \multicolumn{3}{c}{ Tumor size } & P \\
\cline { 2 - 5 } & $\mathrm{T} 1$ & $\mathrm{~T} 2$ & 8 & \\
\hline Alive & 17 & 8 & 8 & $0.011^{*}$ \\
Death & 2 & 8 & 16 & \\
All & 19 & 16 & &
\end{tabular}

*Chi-square P value.

\begin{tabular}{|c|c|c|c|}
\hline \multirow{2}{*}{ Immunostaing } & \multicolumn{2}{|c|}{ Outcome } & \multirow[t]{2}{*}{$\mathrm{P}$} \\
\hline & Alive & Death & \\
\hline Moderate/Strong & 13 & 1 & \\
\hline Negative/focal/weak & 20 & 17 & \\
\hline All & 33 & 18 & $0.005 * / 0.010^{\#}$ \\
\hline
\end{tabular}

${ }^{*}$ Chi-square $\mathrm{P}$ value. ${ }^{*}$ Fisher exact test $\mathrm{P}$ value. 
Eighteen females died after recurrence or metastasis and the remaining females were followed-up for at least 18 months after surgery (Table 1).

Analysis of the gene expression by RT-PCR demonstrated subexpression in 43 dogs, while 8 dogs overexpressed $\mathrm{Cav}-1$ when compared to a pool of normal mammary gland tissue (Figure 3). These females were diagnosed as solid carcinomas (4), complex carcinoma (2), fibrosarcoma (1), and a tubulopapillary carcinoma without any correlation. A comparison between RT-PCR and survival time showed that for the overexpressed samples, two had died and 6 were alive after 18 months. For the 43 subexpressed samples, 8 had died and 35 were alive after 18 months. These figures show a high percentage (84.3\%) of animals with a subexpression of the cav-1 gene (Table 6).

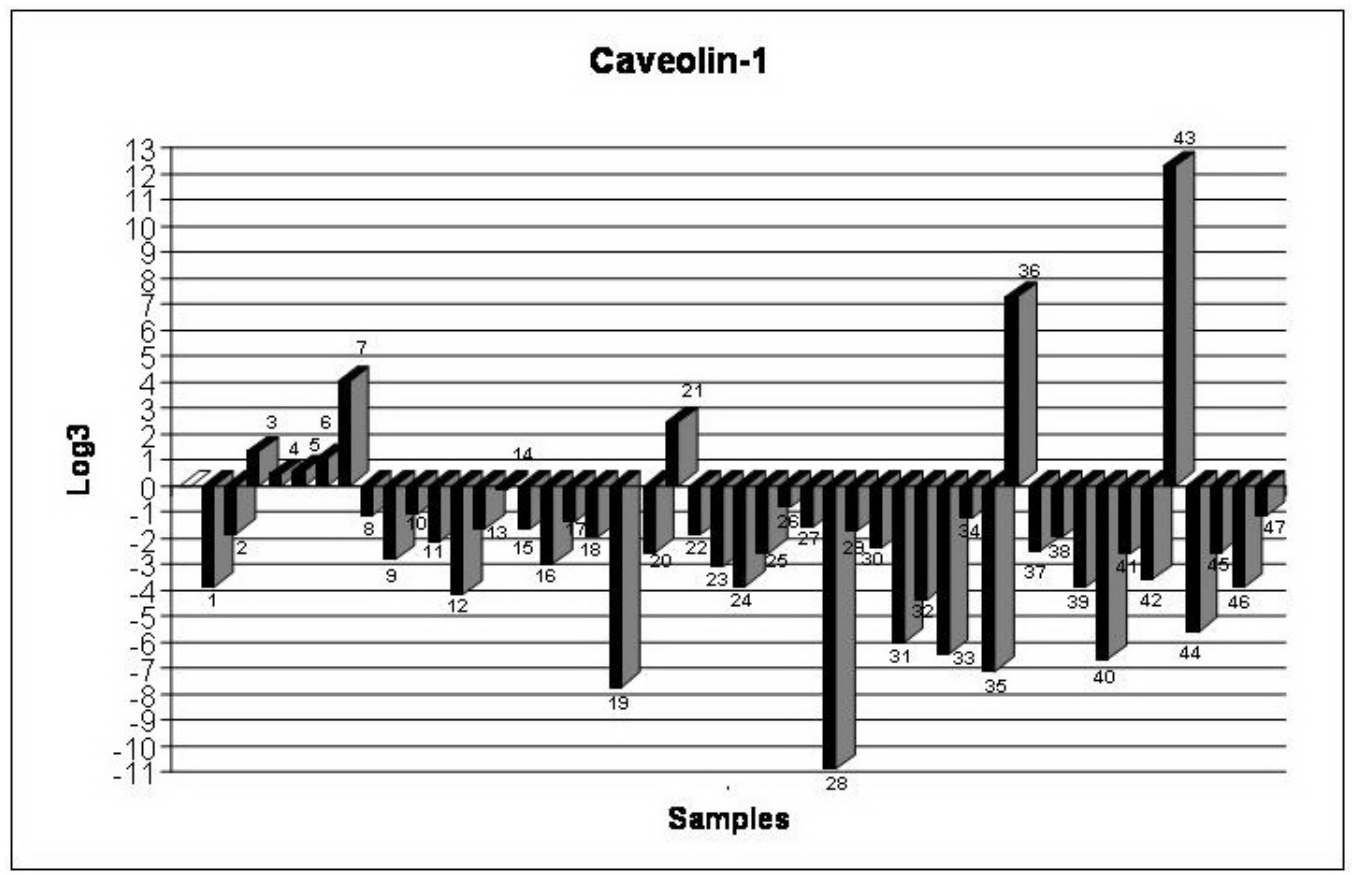

Figure 3. Quantitative gene expression of caveolin-1 in 47 canine mammary gland neoplasms (black). A pool of normal canine mammary gland (control), plotted as the first bar (white), is equal to zero.

Table 6. Correlation between expression of caveolin-1 determined by real-time PCR and overall survival time for 51 dogs with mammary gland neoplasia.

\begin{tabular}{lcrr}
\hline Caveolin-1 expression & \multicolumn{2}{c}{ Overall survival time in months } \\
\cline { 2 - 4 } & $<6$ & $6-18$ & $>18$ \\
\hline Subexpressed & 5 & 3 & 36 \\
Overexpressed & 1 & 1 & 6 \\
All & 6 & 4 & 41 \\
\hline
\end{tabular}


Metastasis occurred in 9 dogs within 18 months following diagnosis. Immunohistochemical examination showed low Cav-1 expression (graded as negative, focal or weak) in all 9 dogs. Similarly, RT-PCR demonstrated that 8 of these had subexpression of Cav-1.

Analysis of the correlation between the cav-1 gene expression as determined by RTPCR and expression of Cav-1 examined by immunohistochemistry demonstrated a genuine trend with no statistical correlation.

\section{DISCUSSION AND CONCLUSION}

According to Liedtke et al. (2007), evaluation of normal breast tissue samples showed no expression of Cav-1 in breast epithelial cells. In myoepithelial cells of ducts and lobuli as well as in blood vessels, expression of Cav-1 was consistently found in normal breast tissue as well as both benign breast tumors and DCIS (ductal carcinoma in situ). Moreover, high Cav-1 expression levels were again observed in mammary myoepithelial cells. Using a monoclonal antibody, no expression of Cav-1 could be found in the epithelial cell component of normal breast tissue or in luminal epithelial cells of benign breast lesions such as radial scars. However, luminal epithelial cells demonstrated Cav-1 expression in $13.4 \%$ of DCIS and $9.4 \%$ of invasive breast cancer specimens.

As expected, there was a prevalence of carcinomas in the group studied. The diagnoses were made at a late stage and many animals showed signs of malignancy at the time of diagnosis, which led to a bad prognosis. Moreover, only three sarcomas were diagnosed. However, when surgery was performed, the majority of bitches survived $(61.7 \%)$. There was a significant correlation between the outcome and the tumor size, which confirms this statement. The majority of cancers studied were simple, which characterized them histopathologically as tubulopapillary.

Although there was a trend, the statistical analysis did not show any significant results based on the assessment of diagnosis and survival. It was observed that if the diagnosis was delayed, the choice of the best practice seemed to help improve the prognosis. There was no statistical correlation between the immunohistochemical marking and the diagnosis. However, this technique showed an important correlation with the outcome, which may render this marker significant.

The caveolin was reduced in this group in accordance with the worst diagnoses. As expected, the molecular study showed subexpression in most samples.

It has been reported that Cav-1 is expressed in normal human mammary epithelial cells and it is down regulated during the progression of cancer. There is a low Cav- 1 expression in non-metastatic primary tumors and a lower expression in highly metastatic tumors. Cells that expressed higher levels of Cav-1 showed a reduced capacity to invade other tissues and produce metastasis (Sloan et al., 2004), which indicates its role as a tumor suppressor (Sloan et al., 2004; Sotgia et al., 2006; Savage et al., 2007). The Cav-1 expression was significantly reduced in breast cancer cells compared with that observed in normal breast tissue and the overexpression of Cav-1 resulted in substantial growth inhibition (Wang et al., 2008). When comparing the expression of the marker and the presence of metastasis, subexpression was observed in these animals, which suggested a significant marker for metastasis, confirmed in both the molecular and immunohistochemical study.

In some cases, overexpression was observed accompanied by high survival rate. How- 
ever, the role of Cav-1 in mammary carcinogenesis is still far from being completely understood. Scientific evidence of a tumor suppressive role of Cav-1 in breast cancer supported by some researchers (Williams and Lisanti, 2005) is contrasted by recent results that strengthen the role of Cav-1 overexpression to promote certain steps of tumorigenesis (Liedtke et al., 2007). When confronted with this controversy one has to assume that the role of Cav-1 as both tumor suppressor and promoter might be context-dependent. While being down regulated in early stage malignancies and thereby mediating growth promoting effects, up-regulation of Cav-1 in the late stage disease might promote resistance against chemotherapeutic agents in colon cancer as well as metastatic properties in prostate cancer (Liedtke et al., 2007). Our results showed a very low expression of the majority of the group in both methods, which could include Cav-1, a suppressor gene in canine mammary tumors as well.

A controversial role for Cav-1 in metastasis has emerged from investigations into various types of cancers (Williams et al., 2004). In addition, this group showed a low Cav-1 immunohistochemical expression in all animals that had metastasis and 8 of $9(88.8 \%)$ gene subexpression in molecular study. This is justified by the possibility of gene mutation occurrence, which alters the protein synthesis. Furthermore, from the nine animals that presented overexpression in relation to the normal sample pool, only three had a bad prognosis and six, $66.7 \%$, were still alive. Williams et al. (2004) had shown that the presence of Cav-1 in mammary tumor cells suppresses tumor growth and metastasis. Complete ablation of Cav-1 (-/-) clearly accelerates tumor onset and growth, as well as the appearance of metastatic disease. In agreement with our results, these authors had previously shown that Cav-1 functions to suppress the processes of tumorigenesis and metastasis in the mammary gland. It was also observed by Sloan et al. (2004) that Cav-1 reduces both primary tumor growth and spontaneous metastasis to lung and bone.

Cav-1 plays an important in vivo role in suppressing early tumor development. Its absence facilitates the appearance and growth of mammary intraepithelial neoplasia lesions. These findings directly support a wealth of clinical, genetic, and cellular evidence implicating Cav-1 as a tumor/transformation suppressor gene (Williams et al., 2003). In cases where there was super-expression this must be related to the expression of other genes.

Liedtke et al. (2007) hypothesized that instead of being an independent prognostic factor alone, Cav-1 might exhibit a more complex function that needs to be evaluated in context with the co-expressed proteins as well as in view of the respective disease stage. This might finally explain the conflicting results described in the scientific literature. Further studies are warranted to understand the role of Cav-1 expression in the disease course of breast cancer as well as its potential as a therapeutic target. Thus, its distinct role in cellular processes may depend on the combination of proteins expressed in the cells rather than on Cav-1 expression itself.

There are only two studies regarding canine mammary tumors and Cav-1 that recognize this marker as a malignant factor, which is in contrast to our study. Amorim et al. (2010) findings are concordant with data previously reported on human breast cancer, documenting Cav-1 overexpression in tumors with unfavorable behavior. For these authors there is a clear association between increased expression of Cav-1 and neoplastic transformation of the epithelium and the data suggest that Cav-1 expression is associated with a more malignant phenotype of canine mammary neoplasia and with vascular invasion and regional lymph node metastasis. In a second article, Pereira et al. (2010) also associated Cav-1 expression with malignant neoplastic transformation in the canine mammary gland. Cav-1 expression may be 
associated with highly malignant subtypes of mammary tumors (basal-like carcinoma), invasion and metastasis, and thus it may play a critical role in the epithelial-mesenchymal transition process. Furthermore, $\mathrm{Cav}-1$ expression is associated with an unfavorable prognosis and is associated with shorter overall survival in canine mammary carcinomas.

The underlying mechanism of in the majority of cases remains to be elucidated. In summary, our findings show that Cav-1 is consistently expressed in canine mammary tumors, contradicting the results presented by Pereira et al. (2010) and Amorin et al. (2010). On univariate analysis, subexpression of Cav-1 was associated with low histologic grade. However, on multivariate analysis, Cav-1 was a significant prognostic factor for metastasis and its down regulation. All these findings may call into question the tumor-suppressive functions of Cav-1 in canine mammary cancer. Further studies are necessary to corroborate the oncogenic properties of Cav-1 in canine mammary tumors (Savage et al., 2007).

\section{ACKNOWLEDGMENTS}

We thank Prof. Dr. Lilian Castiglioni for help in the development of the project; to Prof. Dr. Felipe Augusto Ruiz Sueiro, Prof. Dr. Noeme S. Rocha and Prof. Dr. Cicero Meneghetti for their support in reading and analyzing the slides; to Prof. Dr. José Antônio Cordeiro for the statistical analysis of study data. To Prof. Dr. Eny M. Goloni-Bertollo, Prof. Dr. Érika C. Pavarino-Bertelli and Prof. Dr. Eloisa H. Tajara for their advice. Research supported by FAPESP (\#05/51936-0).

\section{REFERENCES}

Allred CD, Harvey JM, Berardo M and Clark GM (1998). Prognostic and predictive factors in breast cancer by immunohistochemical analysis. Mod. Pathol. 11: 155-168.

Amorim I, Lopes CC, Faustino AM and Pereira PD (2010). Immunohistochemical expression of caveolin-1 in normal and neoplastic canine mammary tissue. J. Comp. Pathol. 143: 39-44.

Bat'ová Z, Bittnerova M, Krenek P and Kyselovic J (2003). Caveolar functions and caveolin structural proteins. Cesk. Fysiol. 52: 166-171.

Bouras T, Lisanti MP and Pestell RG (2004). Caveolin-1 in breast cancer. Cancer Biol. Ther. 3: 931-941.

Chen ST, Lin SY, Yeh KT, Kuo SJ, et al. (2004). Mutational, epigenetic and expressional analyses of caveolin-1 gene in breast cancers. Int. J. Mol. Med. 14: 577-582.

Cordeiro JA (1987). Analysis of Dependency. Relatório Técnico $N^{\circ}$ 48/87. Instituto de Matemática e Estatística, Unicamp, Campinas.

Elsheikh SE, Green AR, Rakha EA, Samaka RM, et al. (2008). Caveolin 1 and Caveolin 2 are associated with breast cancer basal-like and triple-negative immunophenotype. Br. J. Cancer 99: 327-334.

Ferreira E, Bertagnolli AC, Cavalcanti MF, Schmitt FC, et al. (2009). The relationship between tumour size and expression of prognostic markers in benign and malignant canine mammary tumours. Vet. Comp. Oncol. 7: 230-235.

Glait C, Tencer L, Ravid D, Sarfstein R, et al. (2006). Caveolin-1 up-regulates IGF-I receptor gene transcription in breast cancer cells via Sp1- and p53-dependent pathways. Exp. Cell Res. 312: 3899-3908.

Lee H, Park DS, Razani B, Russell RG, et al. (2002). Caveolin-1 mutations (P132L and null) and the pathogenesis of breast cancer: caveolin-1 (P132L) behaves in a dominant-negative manner and caveolin-1 (-/-) null mice show mammary epithelial cell hyperplasia. Am. J. Pathol. 161: 1357-1369.

Liedtke C, Kersting C, Burger H, Kiesel L, et al. (2007). Caveolin-1 expression in benign and malignant lesions of the breast. World J. Surg. Oncol. 5: 110.

Mercier I, Casimiro MC, Wang C, Rosenberg AL, et al. (2008). Human breast cancer-associated fibroblasts (CAFs) show caveolin-1 downregulation and RB tumor suppressor functional inactivation: Implications for the response to hormonal therapy. Cancer Biol. Ther. 7: 1212-1225.

Pereira PD, Lopes CC, Matos AJ, Cortez PP, et al. (2010). Caveolin-1 in diagnosis and prognosis of canine mammary 
tumours: comparison of evaluation systems. J. Comp. Pathol. 143: 87-93.

Savage K, Lambros MB, Robertson D, Jones RL, et al. (2007). Caveolin 1 is overexpressed and amplified in a subset of basal-like and metaplastic breast carcinomas: a morphologic, ultrastructural, immunohistochemical, and in situ hybridization analysis. Clin. Cancer Res. 13: 90-101.

Shajahan AN, Wang A, Decker M, Minshall RD, et al. (2007). Caveolin-1 tyrosine phosphorylation enhances paclitaxelmediated cytotoxicity. J. Biol. Chem. 282: 5934-5943.

Sloan EK, Stanley KL and Anderson RL (2004). Caveolin-1 inhibits breast cancer growth and metastasis. Oncogene 23: 7893-7897.

Sorenmo KU, Kristiansen VM, Cofone MA, Shofer FS, et al. (2009). Canine mammary gland tumours; a histological continuum from benign to malignant; clinical and histopathological evidence. Vet. Comp. Oncol. 7: 162-172.

Sotgia F, Rui H, Bonuccelli G, Mercier I, et al. (2006). Caveolin-1, mammary stem cells, and estrogen-dependent breast cancers. Cancer Res. 66: 10647-10651.

Vandesompele J, De Preter K, Pattyn F, Poppe B, et al. (2002). Accurate normalization of real-time quantitative RT-PCR data by geometric averaging of multiple internal control genes. Genome Biol. 3: RESEARCH0034.

Wang Y, Yu J and Zhan Q (2008). BRCA1 regulates caveolin-1 expression and inhibits cell invasiveness. Biochem. Biophys. Res. Commun. 370: 201-206.

WHO (2007). World Health Organization-Air Force Institute of Pathology Classification System for Canine Mammary Tumors. Available at [http://www.who.int/en/]. Accessed July 5, 2009.

Williams TM and Lisanti MP (2005). Caveolin-1 in oncogenic transformation, cancer, and metastasis. Am. J. Physiol. Cell Physiol. 288: C494-C506.

Williams TM, Cheung MW, Park DS, Razani B, et al. (2003). Loss of caveolin-1 gene expression accelerates the development of dysplastic mammary lesions in tumor-prone transgenic mice. Mol. Biol. Cell 14: 1027-1042.

Williams TM, Medina F, Badano I, Hazan RB, et al. (2004). Caveolin-1 gene disruption promotes mammary tumorigenesis and dramatically enhances lung metastasis in vivo. Role of Cav-1 in cell invasiveness and matrix metalloproteinase (MMP-2/9) secretion. J. Biol. Chem. 279: 51630-51646.

Williams TM, Sotgia F, Lee H, Hassan G, et al. (2006). Stromal and epithelial caveolin-1 both confer a protective effect against mammary hyperplasia and tumorigenesis: Caveolin-1 antagonizes cyclin D1 function in mammary epithelial cells. Am. J. Pathol. 169: 1784-1801.

Zhu H, Weisleder N, Wu P, Cai C, et al. (2008). Caveolae/caveolin-1 are important modulators of store-operated calcium entry in Hs578/T breast cancer cells. J. Pharmacol. Sci. 106: 287-294. 